\title{
Development and evaluation of a spatially explicit habitat suitability model for River Red Gum on the Murray River using an inundation model
}

\author{
$\underline{\text { Linda E. Merrin }}^{\mathrm{a}}$ and Carmel A. Pollino ${ }^{\mathrm{a}}$ \\ ${ }^{a}$ CSIRO Land and Water GPO Box 1666 Canberra 2601 \\ Email: Linda.Merrin@csiro.au
}

\begin{abstract}
The River Red Gum (Eucalyptus camaldulensis) is a widely distributed tree species occurring in frequently flooded riparian habitats and wetlands throughout the Murray-Darling Basin. River Red Gums providing important habitat and contribute to maintaining ecosystem health. River regulation in the MurrayDarling Basin has greatly altered the natural flow regime in many river catchments leading to the degradation of riparian and wetland ecosystems, including the condition of many River Red Gum communities.
\end{abstract}

The Murray-Darling Basin Plan aims to supply environmental water to sustain areas of ecologically significant floodplain communities. This is to be achieved through regional and basin-scale environmental watering plans aimed at returning flows to the river system to maintain ecological function. Environmental watering plans often specify flow peaks that are needed to maintain environmental assets, however the spatial context to the inundation of surrounding wetlands and floodplains is often limited. There are few spatial floodplain models for predicting the ecological outcomes of different river flows in the Murray-Darling Basin.

Habitat suitability models are typically static representations of a biophysical environment that profile a species environmental requirements. Such models are often used to predict the suitability of habitat to facilitate a species recruitment or persistence under specific conditions. Habitat suitability models are often used by resource managers to predict the outcomes of different management strategies, including determining the flow requirements and the potential outcomes of different environmental flow releases. This paper introduces a spatial habitat suitability model for use in assessing the habitat suitability for the iconic River Red Gum. The model considers flow as the main driver, with flows being represented as peaks and durations for the maintenance of River Red Gums at two reaches along the Murray River. The hydrological preferences of the River Red Gum forest and woodland varieties were combined to get a single inundation return interval range, with the effect of inundation duration also considered.

The RiM-FIM inundation model was used to represent the flood extent of flows at each site, with spatial envelopes of habitat suitability determined based on inundation return intervals. The affect of land use was considered by removing towns and agricultural areas from the study area. The predicted extents were compared to observed data and the model outcomes were evaluated by calculating the omission and commission errors. The model outcomes suggested predictions of extent were improved when duration was excluded. Correcting for land use further increased the accuracy of the model.

As part of this paper, we discuss improvements to our approach, including improvements in model conceptualization. The model currently only considers the maintenance requirements of mature River Red Gums. However, different parts of the lifecycle have different watering requirements. Expanding the model to include different lifecycles would lead to a more holistic approach to modelling habitat suitability for River Red Gums.

Another potential improvement is in representation of floodplain inundation. The model currently uses a static representation of floodplain inundation, with the same flow at the gauge assumed to have the same inundation pattern. However, flooding over floodplains is highly dynamic, with changes to land use and development of infrastructure influencing the patterns and extents of inundation. Using a hydrodynamic modelling approach may provide a more accurate representation of the floodplain inundation process.

Keywords: $\quad$ Habitat suitability modelling, River Red Gum, Murray River 
Merrin and Pollino, Development of a spatially explicit habitat suitability model using inundation.

\section{INTRODUCTION}

The River Red Gum (Eucalyptus camaldulensis) is one of the most widely distributed tree species in Australia, and one of the most dominant tree species in the Murray-Darling Basin (Rodgers and Ralph, 2010; Roberts and Marston, 2011). An iconic symbol of inland rives, it is a long lived, medium to tall tree and forms both forests and woodlands. The River Red Gum is found in frequently flooded areas and along creek lines and in wetlands. The River Red Gum is ecologically important, providing habitat and resources to aquatic and terrestrial fauna. River Red Gum communities generally require inundation for both maintenance and recruitment, where the frequency and duration of these flood events is important (Rodgers and Ralph, 2010; Roberts and Marston, 2011).

River regulation throughout the Murray-Darling Basin has altered the natural flow regime, particularly the frequency, size and duration of flood events (CSIRO, 2008). Along the Murray River, the construction of the Hume Dam in 1934, Yarrawonga Weir in 1939 and Dartmouth Dam in 1978, as well as the construction of levees and regulators for the purposes of irrigation and town water supply has greatly altered the flow regime. This has reduced the occurrence of partial flooding and caused a seasonal shift in peak flows due to the delivery of irrigation water to downstream users (Bren, 1998; CSIRO, 2008). River regulation has led to the degradation of riparian and wetland ecosystems, including the condition of River Red Gum communities (Bacon et al. 1993).

In 2007 the Water Act was enacted and included a plan for the management of the Murray-Darling Basin's water resources. Known as the Basin Plan, the purpose of this plan is to manage the water resources in a way that optimizes both the economic, social and environmental outcomes, with basin wide objectives for water dependent ecosystems (MDBA, 2012). In floodplains, these objectives focus on supplying environmental water to sustain areas of ecologically significant communities by returning a more variable flow regime to the rivers which allows the rivers to reconnect to floodplains for a duration and frequency that maintains ecological function in these communities (MDBA, 2012). This is achieved through environmental watering plans which specify the flow volumes that are needed to maintain environmental assets. A limit of this approach is that little spatial context to the inundation of surrounding wetlands and floodplains are provided. For example, in the Murray-Darling Basin, spatial models for predicting the ecological outcomes of flows have been limited.

Habitat suitability models are typically static representations of a biophysical environment that profile a species environmental requirements (for examples see Hirzel, et al., 2001). Such models are often used to predict the likelihood of species recruitment or persistence in a specific habitat under certain conditions. Water, land and natural resource managers use these models to predict the outcome of management strategies, including determining flow requirements and the potential outcomes of environmental flows.

Here we present a spatial model that assesses habitat suitability for the River Red Gum. The model considers flow as the main driver, with flows being represented as peaks and durations for the maintenance of the River Red Gum along stretches of the Murray River. The River Murray Floodplain Inundation Model (RiM-FIM; Overton et al., 2006; Penton and Overton, 2007) was used to represent the flood extent of flows in two Murray River reaches, with spatial envelopes of habitat suitability determined. These predicted extents were compared to observed data and the model outcomes were evaluated using confusion matrices. In the discussion, we consider the potential sources of uncertainty in the model and discuss future improvements to the method.

\section{METHOD}

\subsection{Study sites}

There are two areas that have been considered in this study. The first area covers the reach from upstream of Tocumwal to Barmah, and uses flows from Murray River at Tocumwal, gauge 409202 (corresponding to zone 3 in RiMFIM, and here after referred to as the Barmah zone). This zone incorporates the BarmahMillewa forest with some agricultural land in the upstream area. The Barmah-Millewa forest is a River Red Gum dominated floodplain sitting mostly within two adjacent National Parks. It is also a Murray River Icon site and is listed under the Ramsar convention. 
The second area covers the river reach from the junction of the Campaspe and Murray rivers at Echuca to Torrumbarry Weir. This reach uses flow data from a combination of gauges: Goulburn River at McCoy Bridge, gauge 405232, Campaspe River at Rochester, gauge 406202 and Murray River at Barmah, gauge 409215 (corresponding to zone 6 in RiMFIM, and here after referred to as the Torrumbarry Weir zone). This zone includes a riparian corridor and agricultural land in the upstream part of the reach, and further downstream, includes the southern end of the River Red Gum forest dominated Gunbower, Koondrook, Perricoota Forests Murray River Icon site.

\subsection{Species hydrological preferences}

River Red Gum flow requirements were used to define suitable areas of habitat on floodplains. Here, we only considered tree maintenance requirements, and not recruitment requirements. We also modelled River Red Gum as a single community, rather than as woodlands and forest. We considered the affect of event duration, considering any duration (i.e. duration is not important; set as $\geq 1$ day duration), and the event duration required by the species for maintenance (Table 1) (Roberts and Marston, 2011).

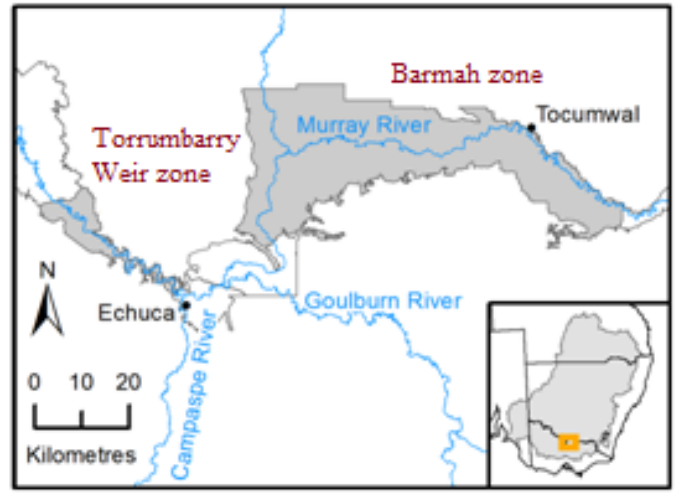

Figure 1. The Barmah zone and the Torrumbarry Weir zone (RiM-FIM zones 3 and 6) used in this study

Table 1. River Red Gum flow requirements

\begin{tabular}{|lcl|}
\hline & Return interval & Duration \\
\hline Modelled & $1: 1-1: 5$ & $\begin{array}{l}\geq 1 \text { day } \\
30 \text { day }\end{array}$ \\
Forest & $1: 1-1: 3$ & 5 to 7 months \\
Woodland & $1: 2-1: 5$ & 2 to 4 months \\
\hline
\end{tabular}

\subsection{Hydrological data}

Observed flows for the gauges in the two zones were collected from the Victorian Water Resources Data Warehouse (http://www.vicwaterdata.net). The Barmah zone record was 103 years (1908-2011), and the overlapping record for the Torrumbarry Weir zone gauges was 41 years $(1970-2011)$. The flow data were analysed to determine the flow volume at the gauge that represents each of the modelled flow return intervals and duration requirements for River Red Gum (Table 1). This was done using a purpose built script in R.

\subsection{Spatial extent mapping}

RiMFIM was used to model the spatial extent of inundation. RiMFIM is a flood inundation model for the Murray River that relates flow at a particular gauge to an extent on the surrounding floodplain using satellite imagery, hydrology data and a DEM (Overton et al. 2006; Penton and Overton, 2007). RiMFIM was used to determine the inundated area corresponding to each of the flow volumes that related to the species requirements. These areas were used to create an envelope of suitable habitat determined by the flow return intervals.

\subsection{Land use}

To improve the prediction of the extent of suitable area, the urban and agricultural lands were removed from
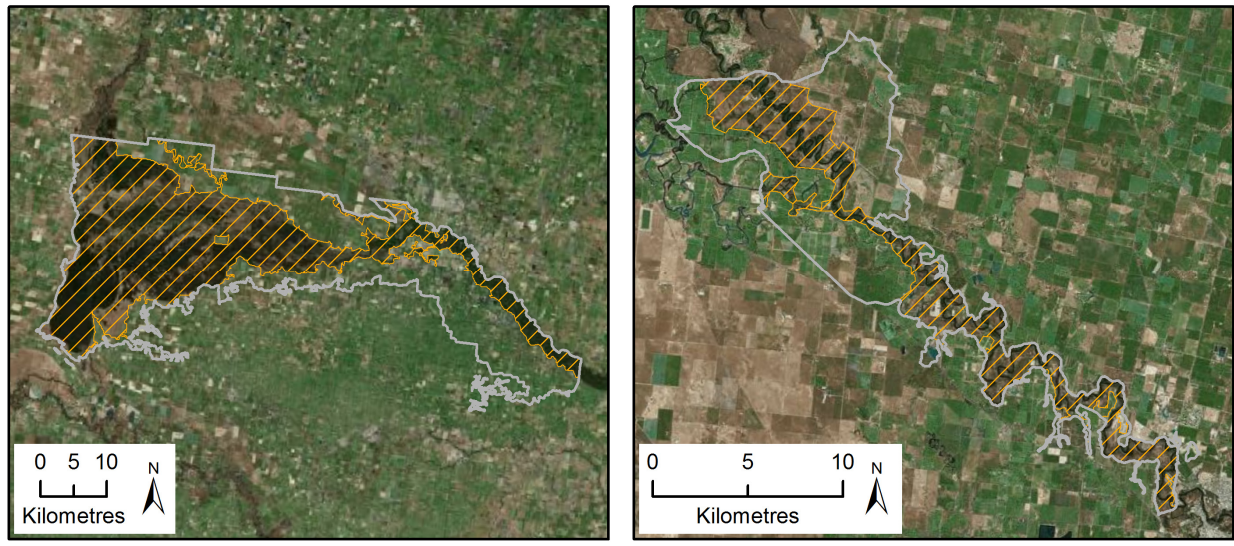

Figure 2. Modified zones 3 and 6, showing the urban and agricultural lands removed 
the zones. This was achieved by redrawing the zone boundary to exclude towns and agricultural areas so that the zone only included areas of native vegetation using Bing Imagery as a base map in ArcGIS (hereafter referred to as modified zones).

\subsection{Validation}

The resulting suitability envelopes were compared to spatial vegetation data collated from each of the states (Ecological Vegetation Classes (EVCs), Victorian Department of Environment and Primary Industries; Vegetation Information System (VIS), New South Wales Office of Environment and Heritage). These datasets were analysed to select vegetation communities that contained River Red Gum. The model was assessed against this observed data, with omission and commission errors calculated to determine the accuracy of the predicted habitat suitability maps.

\section{RESULTS}

Analysis of the flow requirements for the maintenance of River Red Gum can be found in Table 2. The 1 day duration flows are a larger flow than those of the multiday flows, indicating that a high volume of water is required to reach the same extent as a longer duration flood.

Evaluation of the model outcomes against observed occurrences of River Red Gum demonstrated that in the Barmah zone, the model accurately predicted presence of red gums in $76 \%$ of the total area, whilst accuracy for predicted absence was $58 \%$. In this case, the accuracy of the prediction increased to $92 \%$ when taking duration into account (Table 3), while the predicted absence remained the same.

The modified zone, which excluded agricultural areas and towns, was better at predicting areas as suitable for both of the 1 day and 30 day durations. However, the commission errors increased for the modified zone to $85 \%$ and $84 \%$ (for 1 day and 30 day durations respectively) compared to the non-modified zone $(42 \%)$ (Table 3$)$. Figure 3 shows the results for the 1 day and 30 day durations for the modified Barmah zone.

Table 4. Omission and commission errors for the Torrumbarry Weir zone

\begin{tabular}{|lrr|}
\hline 1 day duration & & \\
\hline & Not suitable & Suitable \\
Absent & $64 \%$ & $50 \%$ \\
Present & $36 \%$ & $50 \%$ \\
\hline 30 day duration & & \\
Absent & Not suitable & Suitable \\
Present & $59 \%$ & $48 \%$ \\
\hline Modified zone & $41 \%$ & $52 \%$ \\
1 day duration & & \\
\hline \multicolumn{3}{|c}{} \\
Absent & Not suitable & Suitable \\
Present & $14 \%$ & $14 \%$ \\
\hline 30 day duration & $86 \%$ & $86 \%$ \\
\hline \multicolumn{3}{|c}{} \\
Absent & Not suitable & Suitable \\
Present & $14 \%$ & $15 \%$ \\
\hline
\end{tabular}

Table 2. Flow requirements $(\mathrm{GL} / \mathrm{d})$ for the maintenance of River Red Gum

\begin{tabular}{|c|c|c|}
\hline \multicolumn{3}{|c|}{ Barmah zone } \\
\hline & 1 day duration & 30 day duration \\
\hline $1: 1$ & 22 & 10 \\
\hline $1: 5$ & 101 & 61 \\
\hline \multicolumn{3}{|c|}{ Torrumbarry Weir zone } \\
\hline & 1 day duration & 30 day duration \\
\hline $1: 1$ & 15 & 10 \\
\hline $1: 5$ & 93 & 57 \\
\hline
\end{tabular}

Table 3. Omission and commission errors for the Barmah zone

\begin{tabular}{|lcc|}
\hline 1 day duration & & \\
\hline & Not suitable & Suitable \\
Absent & $58 \%$ & $24 \%$ \\
Present & $42 \%$ & $76 \%$ \\
\hline 30 day duration & & \\
\hline & Not suitable & Suitable \\
Absent & $58 \%$ & $8 \%$ \\
Present & $42 \%$ & $92 \%$ \\
\hline \hline Modified Zone & & \\
1 day duration & & \\
\hline & Not suitable & Suitable \\
Absent & $15 \%$ & $8 \%$ \\
Present & $85 \%$ & $92 \%$ \\
\hline 30 day duration & & \\
\hline & Not suitable & Suitable \\
Absent & $16 \%$ & $5 \%$ \\
Present & $84 \%$ & $95 \%$ \\
\hline
\end{tabular}

Event duration in the Torrumbarry Weir zone did not influence the models ability to predict suitable habitat $(50 \%$ for 1 day duration compared to $52 \%$ for 30 day duration, and $86 \%$ for the modified zone 1 day duration compared to $85 \%$ for the modified zone 30 day duration) (Table 4). However, the modified zone was much better at correctly predicting areas as suitable compared to the nonmodified zones ( $86 \%$ compared to the $50 \%$ for the 
Merrin and Pollino, Development of a spatially explicit habitat suitability model using inundation.

1 day duration, and $85 \%$ compared to $52 \%$ for the 30 day duration) (Table 4 ).

Similarly to the Barmah zone, in the Torrumbarry Weir zone there was an increase in commission errors for the non-modified zone compared to the modified zone (36\% and $41 \%$ compared to $86 \%$ ). Figure 4 shows the results for the 1 day and 30 day duration for the modified zone.
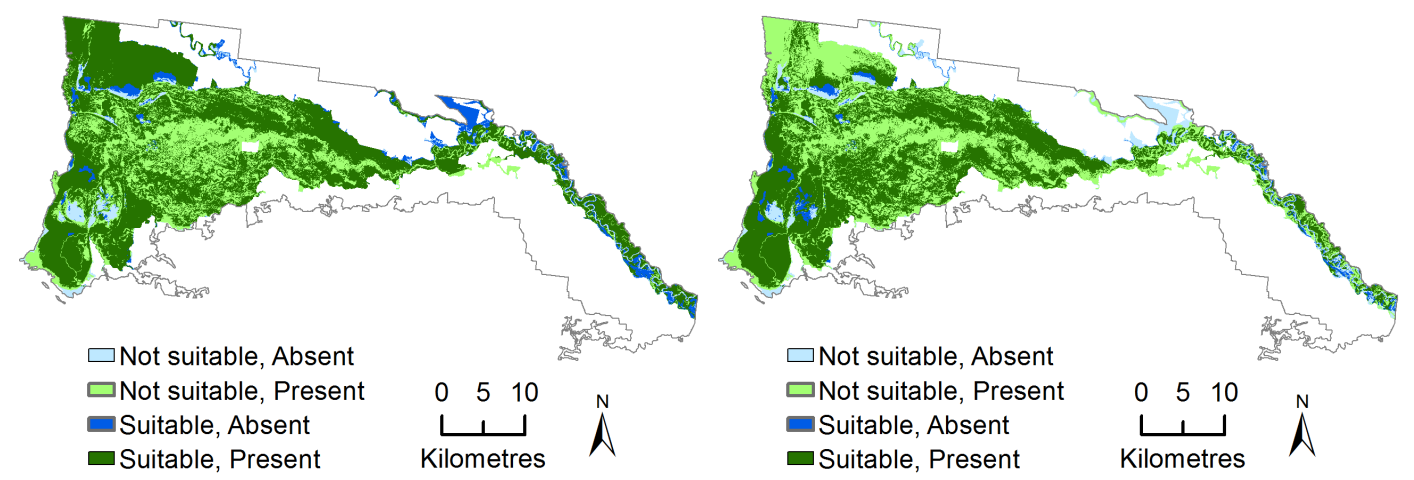

Figure 3. Mapped Barmah zone confusion matrix for the 1 day and 30 day duration for the modified zone
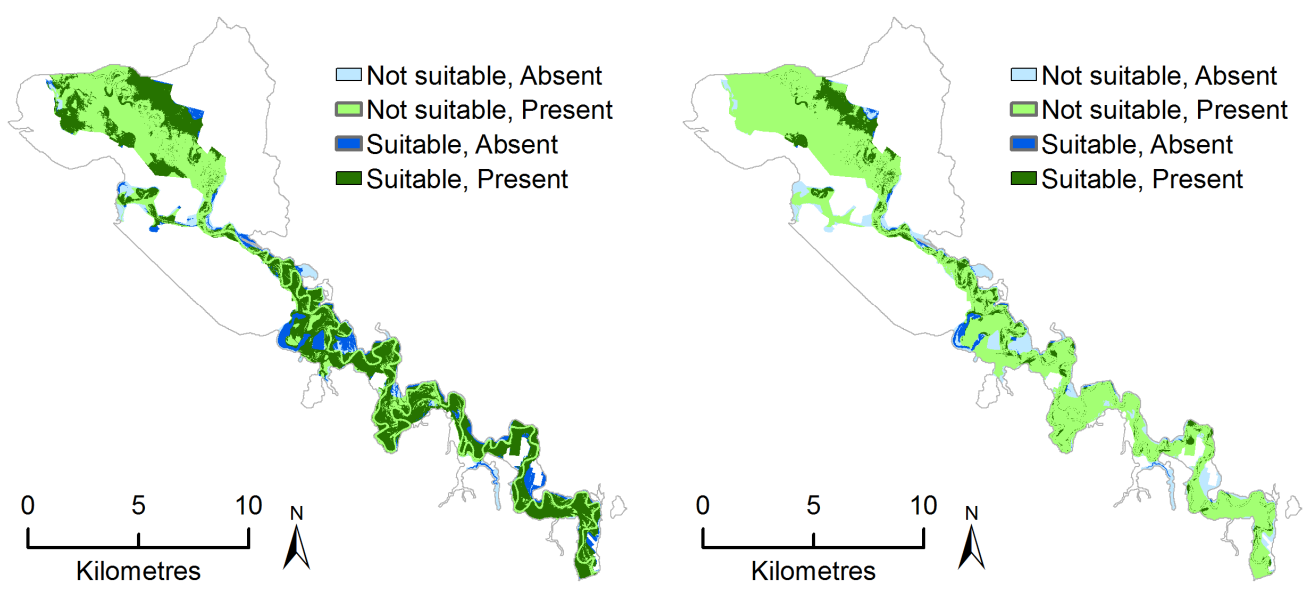

Figure 4. Mapped Torrumbarry Weir zone confusion matrix for the 1 day and 30 day duration for the modified zone

\section{DISCUSSION}

This paper introduces a model to predict the area of habitat suitable for River Red Gums, using flow as the key driver. Here we evaluate the performance of the model. The model is designed to spatially define areas of suitable River Red Gum habitat on floodplains, rather than representing hydrologic requirements without a spatial context, which is typically done in water resource planning. In the discussion, we overview the model limitations, including the limitations of the input and validation data and the model conceptualization. We also discuss the potential for future model improvements.

The primary assumption underlying the model is that inundation is the main factor in determining the distribution of River Red Gums, and land use can constrain distribution. While inundation is important for seed germination and seedling establishment (Roberts and Marston, 2011), River Red Gums can also access groundwater and soil moisture (Ralph and Rodgers, 2010). Groundwater is believed to be a very important source of water, with River Red Gums generally having a deep root system (Bren, 1988; Ralph and Rodgers, 2010). Flood inundation however, can be important for tree health (Ralph and Rodgers, 2010), with inundation resulting in vigorous growth (Bren, 1988; Roberts and Marston, 2011). Inundation can also be important for recharging soil moisture (Ralph and Rodgers, 2010).

RiMFIM was used to relate flow at a gauge to an area flood extent. RiMFIM is a static inundation model and does not consider antecedent conditions. The main assumption in this model is that the same flow at the gauge has the same inundation pattern. However, the structure and function of floodplains change with land 
use changes, floodplain infrastructure development, natural and human channel modifications, economic (urbanisation and agricultural) development, climate variability and flow variability. Another limitation is the input flow data. We used observed flow to derive flood metrics to define areas considered suitable for River Red Gums. However, this flow record was limited in flow length, and there were some missing data. Short periods of flow observation may not be sufficiently long enough to cover an adequate range of climate extremes and any trends in river management and development that have occurred, increasing the data uncertainty (van Dijk et al., 2008). The limited flow record in the Torrumbarry Weir zone may not have been long enough to capture rare flow events. However, Kennard et al. (2010) found that flow records of only 15 years are long enough to detect events.

Here, we limited analysis to flow return intervals and duration. Flood regime (sequencing and timing) is important for mature trees and their understory communities (Ralph and Rodgers, 2010). River Red Gum forests require more frequent inundation than woodlands, and as a result typically have a dense understory, whilst the understory of the woodland variety is sparser. Changes in the timing of flooding can lead to changes in vegetation species composition due to competition (Roberts and Marston, 2011). A model improvement would be to model River Red Gum forest and woodland separately, rather than grouping them together as is currently modelled. Validating this model would be difficult, as the New South Wales VIS data contains information on woody vegetation including species information, but only lists the dominant species. It would therefore not possible to separate River Red Gum forest from woodland in this dataset. The Victoria spatial vegetation data is a combination of floristic information as well as ecological characteristics, focusing at the community level. It covers all vegetation types, and has detailed attribute data. It would therefore be possible to separate River Red Gum forest from woodland.

In conceptualizing the model, we have limited species flow requirements to maintenance, which is only one part of the overall life cycle. The lifecycle stage that is most vulnerable to change is the germinant-seedling stage (Merritt et al., 2010), which have specific flow requirements. As individual germinants successfully pass from germinant-seedling to juvenile stage, hydrologic processes (e.g. water availability) may be a key determinant of growth, long-term survival and mortality (Merritt et al., 2010). Flood events also provide the main dispersal mechanism for River Red Gum seeds (Roberts and Marston, 2011). Seed germination and seedling establishment are more successful on soils with high moisture content, and is most successful with a receding flood during spring or early summer (Ralph and Rodgers, 2010). However, establishment can result from an increase in soil moisture due to rainfall (Roberts and Marston, 2011). Water depth is also important for establishment, as seedlings suffer from stress as a result of prolonged inundation. Depth is less important once the seedlings have developed into saplings (Roberts and Marston, 2011). Information on inundation depth can be gained from RiMFIM, but the model does not model water retention (Penton and Overton, 2007). Representation of the whole lifecycle of a tree, and understanding the relationship between water and vegetation life stage would allow for a more holistic representation of River Red Gum in a spatial model.

Another aspect that could be incorporated into model conceptualisation is the role River Red Gums have in providing a healthy ecosystem. Francis and Sheldon (2002) found that River Red Gums provide an important source of bioavailable carbon, with the form of inputs being directly influenced by the variable flow regime. In low flow periods, River Red Gum leaf litter accumulates on the floodplain, and as floodplains inundate, the accumulated organic matter is inundated, releasing carbon, which becomes available to aquatic organisms as food, contributing to overall ecosystem health (Francis and Sheldon, 2002). In circumstances when there is prolonged drought, large amounts of released carbon can be detrimental, resulting in hypoxic blackwater events, which have a detrimental impact on aquatic fauna (King et al., 2012).

Another limitation to this model is its static representation of River Red Gums. Dynamic approach to modelling floodplain vegetation can allow for a more representative conceptualisation of floodplains, rather than modelling them as they are only at the present (Olsen et al., 2000). However, despite floodplains being characterized by disturbance, previous studies have found that their composition is relatively constant, making the approach used here valid (Ward et al., 2002).

\section{CONCLUSION}

The model introduced in this study predicts the distribution of River Red Gum using flood inundation extent. It allows natural resource managers to assess the potential outcomes of management strategies for environmental flows using inundation and knowledge of the species watering requirements. It allows environmental watering requirements to be represented spatially, assisting in future planning of floodplain watering and management. 
Merrin and Pollino, Development of a spatially explicit habitat suitability model using inundation.

This model approach has been expanded to other vegetation species on the Murray River. It could also be expanded into other areas that have a suitable inundation model. At present, the model uses a static representation of inundation and only considers one stage of the species life cycle. Possible future model improvements include using a hydrodynamic model to represent water depth and seasonality, and to include watering requirements for each stage of the life cycle. Further work could also be carried out to separate the forest and woodland varieties, with validation conducted using a combination of existing data and fieldwork. Overall, this model has the potential to represent habitat suitable for River Red Gums on floodplains using species hydrological preferences and inundation data, and represents a simple way to predict the potential change in distribution given alternative flow scenarios.

\section{REFERENCES}

Bacon, P.E., Stone, C., Binns, D.L., Leslie, D.J. and Edwards, D.W. (1993). Relationships between water availability and Eucalyptus camaldulensis growth in a riparian forest. Journal of Hydrology, 150, 541-561.

Bren, L.J. (1988). Effects of river regulation on flooding on a riparian red gum forest on the River Murray, Australia. Regulated River: Research and Management, 2, 65-77.

CSIRO. (2008). Water availability in the Murray-Darling Basin. CSIRO Murray-Darling Basin Sustainable Yields Project, CSIRO, Australia, p.67. www.csiro.au/mdbsy.

Francis, C. and Sheldon, F. (2002). River Red Gum (Eucalyptus camaldulensis Dehnh.) organic matter as a carbon source in the lower Darling River, Australia. Hydrobiologia, 481, 113-124.

Hirzel, A.H., Helfer, V. and Metral, F. (2001). Assessing habitat-suitability models with a virtual species. Ecological Modelling, 145, 111-121.

Kennard, M.J., Mackay, S.J., Pusey, B.J., Olden, J.D. and Marsh, N. (2010). Quantifying uncertainty in estimation of hydrologic metrics for ecohydrological studies. River Research and Applications 26(2), 137156.

King, A.J., Tonkin, Z. and Lieshcke, J. (2012). Short-term effects of a prolonged blackwater event on aquatic fauna in the Murray River, Australia: considerations for future events. Marine and Freshwater Research, $63,576-586$.

MDBA. (2012). Water Act 2007 - Basin Plan 2012. Murray Darling Basin Authority, Canberra. 245 pp.

Merritt, D.M., Scott, M.L., Poff, L.N., Auble, G.T. and Lytle, D.A. (2010). Theory, methods and tools for determining environmental flows for riparian vegetation: riparian vegetation-flow response guilds. Freshwater Biology, 55, 206-225.

Olsen, J., Beling, P. and Lambert, J. (2000). Dynamic Models for Floodplain Management. Journal of Water Resources Planning and Management, 126, 167-175.

Overton, I.C., McEwan, K., Gabrovsek, C. and Sherrah, J.R. (2006). The River Murray Floodplain Inundation Model (RiM-FIM) Hume Dam to Wellington. CSIRO Water for a Healthy Country Flagship Technical Report 2006, Adelaide. 42 pp.

Penton, D.J. and Overton I.C. (2007). Spatial Modelling of Floodplain Inundation Combining Satellite Imagery and Elevation Models. In Oxley, L. and Kulasiri, D. (eds) MODSIM 2007 International Congress on Modelling and Simulation. Modelling and Simulation Society of Australia and New Zealand, December 2007, http://mssanz.org.au/MODSIM07/papers/23_s31/SpatialModeling_s31_Penton.pdf.

Roberts, J. and Marston, F. (2011). Water regime for wetland and floodplain plants: a source book for the Murray-Darling Basin, National Water Commission, Canberra.

Rogers, K. and Ralph, T. (2010). Floodplain Wetland Biota in the Murray-Darling Basin. Water and Habitat Requirements. CSIRO Publishing.

Van Dijk, A., Kirby, J.M., Paydar, Z., Podger, G., Mainuddin, M., Marvanek, S. and Peña-Arancibia, J. (2008). Uncertainty in river modelling across the Murray-Darling Basin. A report to the Australian Government from the CSIRO Murray-Darling Basin Sustainable Yields Project. Canberra: CSIRO.

Ward, J., Malard, F. and Tockner, K. (2002). Landscape ecology: a framework for integrating pattern and process in river corridors. Landscape Ecology, 17, 35-45. 